\title{
OFF-LABEL USE OF ANTIPSYCHOTICS AND ANTIDEPRESSANTS- A DOUBLE EDGED SWORD - OBLIGES A CLOSE MONITORING
}

\author{
PANKAJ PANT*1, PUNEET DHAMIJA², YUSRA AHMAD³, PALLAVI SRIVASTAVA². \\ *'School of Pharmaceutical and Population Health Informatics, DIT University, Dehradun-248009, Uttarakhand, India. \\ 2Dept. of Pharmacology, AllMS, Rishikesh- 249203, Uttarakhand, India. \\ 3Faculty of Pharmacy (UTU), Dehradun-248007, Uttarakhand, India. \\ Corresponding author address \\ Pankaj Pant, Ph.D., School of Pharmaceutical and Population Health Informatics, DIT University, Dehradun. \\ E-mail: drxpankajpant@gmail.com. \\ Mobile No.- +91-8474932009
}

\begin{abstract}
Objective: - To determine the level of scientific support and frequency of off-label prescribing pattern for antipsychotics and antidepressants. In addition to monitoring adverse drug reactions in patients prescribed with antipsychotic and antidepressant drugs.Materials and Method: -An observational prospective and retrospective study was carried for the capturing and monitoring of off-labeled uses and associated ADR's of antipsychotics \& antidepressants, in a Tertiary Care Teaching Hospital for six months. Individual drug package insert (US-FDA) was used as a reference basis to ascertain the offlabel prescribing. The data was analyzed aimed at establishing a causal association between drug ADRs combination using standardized WHO-UMC Causality Assessment Scale.Results: - A total no. of 549 patients were involved in the study with a mean age of $37.34 \pm 12.618$ years (range 10-82 years). The male patients comprised $233(42.44 \%)$ and $316(57.55 \%)$ of females. A total of 1543 drugs prescribed in which the $702(45.49 \%)$ were antipsychotic and antidepressants. The total no. of drug indication was 560, and 221 (31.48\%) of drugs prescribed without any indication. Amitriptyline 137(19.51\%) was the most commonly prescribed drug followed by the Escitalopram 120(17.09\%), Clonazepam $85(12.10 \%)$, Fluoxetine 79(11.25\%), Sertraline 46(6.55\%), etc. The total no. of 238 ADR's was reported in the sum of both retrospective and prospective studies. The most frequently drug causing ADR was reported as Escitalopram 83(34.72\%) followed by Fluoxetine $59(24.68 \%)$, Sertraline 33(13.80\%), Paroxetine 15(6.27\%) and Amitriptyline 14(5.85\%).Conclusion: - In our study, we noticed that the prescribing of off-label medicines is common in psychiatric practice, but this is not restricted to psychiatric setup only; other departments are also involved prescriptions of psychotherapy drugs used in different ailments. The outcomes of our study have highlighted a requirement to ensure a lot of scientific evidence about the risks and benefits of off-label medications expanding the accountability of doctors towards safe medication practices.
\end{abstract}

Key words: Off-label use, Antipsychotics \& Antidepressants, Adverse drug reaction. 


\section{WHAT IS ALREADY KNOWN ABOUT THIS SUBJECT}

As we know the trend to prescribe off label drugs is common among clinical practice. But unfortunately, this is a gray area, that wants to be explored the broad concern about safety and efficacy issue upstretched by inappropriate use of the drugs.

\section{WHAT THIS STUDY ADDS}

- This study examines off-label indications for antipsychotics and antidepressants and determine the level of scientific support for off-label prescribing.

- Also, here we screened adverse drug reactions in patients prescribed with antipsychotic and antidepressant drugs.

- We formulated a database registry of labeled versus off-labeled antipsychotics and antidepressants prescribed in tertiary care and reported at ADR Monitoring Centre.

\section{INTRODUCTION}

Off-label prescription of antipsychotic and antidepressant drugs has become a common phenomenon in medical practice. In recent years there has been an increasing trend in off label prescribing especially for the pediatrics and geriatrics population because medicines are less normally tested in this age group, due to lack of available standard and alternate treatment therapies, raising safety concerns in these groups.

\section{Off-label Use of Medications}

When the medicine prescribes to patients for the treatment of a disease or condition, generally patients assume that the drug has been approved and valid for the uses. But over-all one-fifth of the prescribed medicines in the United States is for users that do not approve by the FDA, these are considered as "off-label" prescription (1).

A medication approves for a particular indication, in a certain dose with the particular dosage formulation and route of administration established by data from clinical trials that have been submitted to and scrutinized by the regulatory bodies (such as DCGI, US-FDA). While the use of a drug for an indication, population such as pregnancy, children and older patient's, dosages form, or the mode of administration which is not mentioned in the drug labeling information and not approved by the drug regulatory agencies; termed as Off-label use (2).

Consequently, here is very essential to understand that the off-label prescribing whether illegal or not. Although it is ethical and acceptable to use drugs in an offlabel manner in case such use is built on sound data and potential evidence. It is considered legal if it does not violate safety guidelines and ethical principles. Studies show that the various medicine prescription, as well as many over the counter (OTC) medications, are been used in an off-label manner for their good outcomes. Off-label prescribing can be advantageous, exclusively when patients have tired after using all other approved choices. Therefore, the off label uses of medicine don't consider as the inappropriate, contradicted, illegal or 
inexperienced use. It can also be viewed as an essential part of the art of psychiatry, but it takes with greater responsibility for the physician as, if the patient undergoes an adverse reaction, liability will rest with the physician and/or their staff (3).

It is well established that the off-label prescribing with a lack of strong scientific evidence has $54 \%$ higher risky then the labeled prescribing with dense scientific shreds of evidence for the adverse reactions outcomes. In psychiatry practice, most of the treatment indications do not mention for a maximum of the prescriptions and this result is lack of epidemiological confirmation on the level to which prescribers recommend the antidepressants and antipsychotics in an off-label manner (4).

\section{Pharmacovigilance}

In the 16th century, Paracelsus believed that any medicinal substance could harm, defines the dose to determine whether the substance is a remedy or poison. Despite this performance and successful observation, 450 years of intervention have failed to provide a definitive definition of an adverse drug reaction, although they all include the opinion that the medical use of any medicine has caused unexpected loss (5).

Pharmacovigilance (PV) itself is a clinical discipline that deals with safety and acts as an indicator of clinical care standards within a nation. It is the exercise aimed at improving patient welfare, monitoring drug safety data in real-life situations and capturing adverse drug events and other drug-related problems throughout the marketing period of the drug life cycle progression.
Pharmacovigilance is described as "the science and activities relating to the detection, assessment, understanding, and prevention of adverse effects or any other drug-related problems" (by World Health Organization) (6).

\section{Establishment of Pharmacovigilance}

After Sulfanilamide tragedy, which responsible for the death of 105 individuals (71 adults plus 34 children) that had been used for the treatment of streptococcal infection since 1932. Pharmacovigilance reveals its origin; it was well-known as a solvent in the form of a Diethylene glycol as syrup then it was banned (7). Thalidomide disaster, which is a revolutionary in the formation and development of pharmacovigilance. In the beginning. Thalidomide single-minded as the safest treatment for nausea and morning sickness in pregnant women, which was in full swing in 1957. It was soon found to be associated with a congenital deformity, in this manner causing severe natal defects in the children of women's who had taken this drug for the duration of pregnancy. Until 1965, Thalidomide was taking out of the market in most nations. But it continued to be used with key precaution and strict supervision, for the treatment of leprosy. At present, its indications have been long to a wideranging of medical conditions (8).

\section{Pharmacovigilance Programme of India}

Now India, Pharmacovigilance was first taking place in 1986 by way of the formal adverse drug reaction monitoring scheme including twelve regional centers, for each of which ensured fifty million populations, under the supervision of Drug Controller of India. In 1998, India linked with the World 
Health Organization (WHO) 'Program for International Drug Monitoring' but then nothing had happened for a decade and it was not getting ahead.

Later in January 2005, the World Bankfunded and WHO sponsored National Pharmacovigilance program (NPP) was launched for India which was retitled on 14 July 2010 by way of "Pharmacovigilance Programme of India" (PvPI) (9).

It was started by Central Drug Standard Control Organization (CDSCO) underneath the assistance of Ministry of Health and Family Welfare in Collaboration thru All India Institute of Medical Sciences (AIIMS) and National Coordinating Centre (NCC). On 15 April 2011, NCC was moved to the Indian Pharmacopoeia Commission (IPC), Ghaziabad (10). It started with the participation of twenty-two ADR monitoring center across the nation-state in the year 2010 and that was increased to 250 by the end of 2018 .

ADRs are identified and reported by the healthcare professional like Physicians, Pharmacists, Nursing officers, dentists, etc. under PvPI through Adverse Drug Reaction Monitoring Centers (AMCs). These Adverse Drug Reaction Monitoring Centers are established all over the nation-state in Medical Institutions those are authorized by the Medical Council of India (MCl) and they are in command for collecting adverse events according to the Standard Operating Procedure (SOP).

\section{Antidepressants}

The development of antidepressants begins from the 1950s and now their uses are very common from the last 25 years. Currently, antidepressants recorded $29 \%$ for off-label propose (11).
These subclasses have different kinds of Adverse drug reactions. Usually, SerotoninNorepinephrine reuptake inhibitors (SNRIS), Selective serotonin reuptake inhibitors (SSRIS), are considered safer than the other subclass and are most frequently prescribed. There are some common adverse reactions of these classes include nausea, headache, sedation, distress, and sexual problems (12).

The Selective Norepinephrine reuptake inhibitors are not safe for the pregnancy, the chance of preterm birth, pregnancy loss, low natal weight, and congenital birth faults. In a study by Nordqvist $C$. et. al, the 69, 448 pregnancies found using Selective Norepinephrine reuptake inhibitors or Tricyclic antidepressants during pregnancy and therein increase the risks of high BP, known as pre-eclampsia. But there is no surety about this whether its due to the depression or by the drug-induced (11).

Only some of the antidepressants are permitted for the management of obsessive-compulsive disorder (OCD), urinary incontinence and major depressive disorder (MDD) in pediatrics. The drugs such as Paroxetine, Citalopram, and Sertraline were studied in clinical trials which don't support the use in the pediatric patient for Major depressive disorder while Venlafaxine has been well studied for generalized anxiety disorder and major depressive disorder, but it didn't show efficacy in pediatrics (13).

A latest systematic review by Shen-Chieh Chang et.al, (2019) indicated that the antidepressant medications are found effective in treating cancer-associated symptoms such as hot flushes, pain, anorexia/cachexia, nausea, and fatigue. 
These are found to be more effective than the placebo in the course of relieving symptoms of depressions in melanoma's patients with effectiveness positively linked to the length of treatment. Apart from this, the antidepressants have been studied for the ability of their anticancer. They have also extended in their study; antidepressants can prevent the development of tumor by increasing cytotoxic activity and modifying cytokine production or by directly introducing cancer cell death and arresting cancer cell prides indirectly by regulating immunity (14).

Recently two new FDA Drug Safety Communications have been published to notify patients and healthcare providers regarding Fluoxetine and with high doses of Citalopram may increase the risk of abnormal heart rhythms or Cardiac Arrhythmias. Fluoxetine has been reported post marketing cases of QT prolongation and Citalopram made recognized as to cause the QT interval extension. The high risk for the patients who suffering heart conditions, hypomagnesemia or hypokalemia which may perhaps lead to Torsade de Pointes (12).

\section{Antipsychotic}

Antipsychotic drugs are well approved by the USFDA for the primary treatment of bipolar disorder and schizophrenia. These drugs have revolutionized the treatment of psychiatric illness. Even though approved in the beginning only for the schizophrenic disorder. Antipsychotic drugs have also been used for numerous disorders including, behavioral disorders, bipolar disorder, psychoses, delirium, depression, autism, dementia, etc. (15).
It is not well understood to what extent these off-label prescriptions are supported by scientific evidence. In the literature survey, we found that the very a smaller number of studies available in Indian context on off-label use of psychotropic medicines. (19).

Hence, to increase the data need a regular audit on off-label use of drugs, because the excess of the data provides an adequate level of scientific evidence on the safety and efficacy of these drugs for off-label prescriptions. (20).

Thus, the objective of this study was to examine off-label indications for antipsychotics and antidepressants in primary care and determine the level of scientific support for off-label prescribing. In addition to monitoring adverse drug reactions in patients prescribed with antipsychotic and antidepressant drugs.

This study will help practitioners to correctly identify off-label prescription of antipsychotic and antidepressant drugs with potential risk minimization and drug utilization approach. The data generated from the study outcome will establish the highest level of scientific evidence and warrant the attention of drug regulatory authorities in revising existing drug status and taking appropriate regulatory decisions.

\section{$>$ MATERIALS AND METHOD}

\section{STUDY DESIGN/DURATION}

- An observational prospective and retrospective study was carried for the capturing and monitoring of off-labeled use as well as associated ADR's of antipsychotics and antidepressants, in a Tertiary Care Teaching Hospital for six months. 
- Authorization from the Institutional Ethics committee was achieved.

- The patients who attend the Outpatient Departments of the hospital and individuals who agreed to give consensus during this period were joined in the study, after the obtaining consensus of the patient or patient's custodian.

- Study population - All patients who had received at least one antipsychotics and antidepressants and/or had any associated ADR's with these medications.

\section{INCLUSION/EXCLUSION CRITERIA Inclusion criteria}

1. Patients with a minimum one off-label prescription of antipsychotics and/or antidepressant medication.

2. Patients of all age groups and both sexes were included.

3. Individuals who understood the intention of the study and were willing to give information about their health status.

4. The previously reported ADR forms available at ADR Monitoring Centre, comprising of at least one suspected drug from the category of antidepressants or antipsychotics.

\section{Exclusion criteria}

1. Patients not willing to participate.

2. Patients having a history of substance abuse

3. Patients with suicidal ideation.

4. Patients suffering from any severe disease such as heart failure, unstable coronary heart disease, progressive kidney, or liver failure.

5. Those unable to comprehend the nature and purpose of study for other reasons.

\section{Data Collection}

- The study methodology included retrospective and prospective analysis of the off-label use antipsychotic and antidepressant medications in clinical practice and data related to their associated ADRs.

- Individual drug package insert (US-FDA) was used as a reference basis to ascertain the off-label prescribing.

The clinical observation of the study comprises 3 phases, 1 st Phase of the study

- The retrospective study was conducted on ADRs reports available at ADR Monitoring Centre, from January 2016 to August 2018.

- A screening log was generated to identify the ADRs related to off-label use of psychiatric medications from stored ADR database.

- The segregated data is then recorded for further analysis.

\section{2nd Phase of the study}

- The prospective analysis of data obtained from all the patients screened with at least one prescription of either antipsychotic and/ or antidepressant drug attending the outpatient (OPD) and inpatients department (IPD).

- The screening log generated using prescription audit method by scanning all the prescriptions contain psychiatric drug received at AllMS Pharmacy (Amrit Pharmacy Store and PM Jan Aushadhi Kendra).

- The suspected ADRs were collected by the investigator under the supervision of treating consultants and pharmacovigilance associate and the data was recorded in spontaneous ADR reporting form and case record form. 
- The off-label indications and ADRs from collected data were identified by performing a cross-check with a given checklist of ADRs.

- The patient experiencing ADRs from use of either antipsychotic and/or antidepressant drug were cross-examined to collect complete information regarding patient demographics, clinical history, and prescription details in addition to drug and reaction related information which recorded on a pre-structured, customized data collection sheet i.e., Case Record Form (CRF).

\section{3rd Phase of the study}

- Causality assessment was done using the WHO-UMC scale. Then details of ADRs were sent to the National Coordinating Centre (NCC) through Vigiflow.

- The collected data was then analyzed at ADR Monitoring center for parameters such as completeness, quality, and authenticity.

\section{Data Analysis}

- The data was analyzed for generating evidence about potential off-label use and associated ADRs of antipsychotic or antidepressant drug used in clinical practice.

- Descriptive statistics have been used for presenting the results using Microsoft Excel.

- The data generated was used for the evaluating clinical significance, efficacy, safety, and benefit/ risk profile of offlabeled use of antipsychotics and antidepressant drugs used in clinical practice.

\section{Data Archival}

- The information collected has been kept confidential and is only used for scientific purpose.

- Recorded data was stored in a structured way in the ADR Monitoring Centre for easy access and retrieval.

\section{$\underline{\text { RESULTS }}$}

\section{- Demographic and morbidity pattern}

A total no. of 549 patients were included in the study with a mean age of $37.34 \pm 12.618$ years (range 10-82 years). Male patients comprised $233(42.44 \%)$ and 316 (57.55\%) of females. [Figure-1].

\section{Sex ratio of the study population}

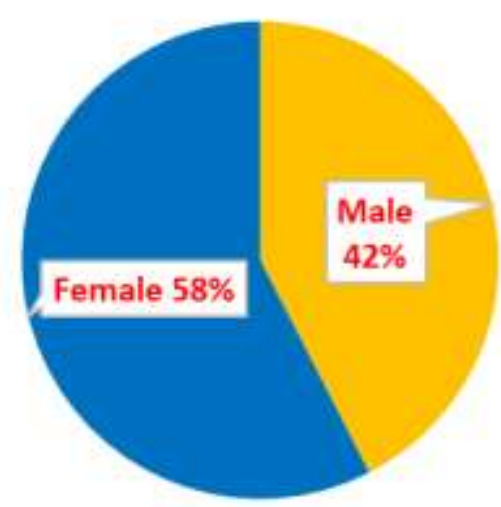


Figure 1- Sex ratio of the patient's population. $(n=549)$

The most patients were middle-aged at the time of their earliest antidepressant prescription (median 37 years, interquartile range 31-50) [Figure-2].

\section{Age wise distribution of the total studied population}

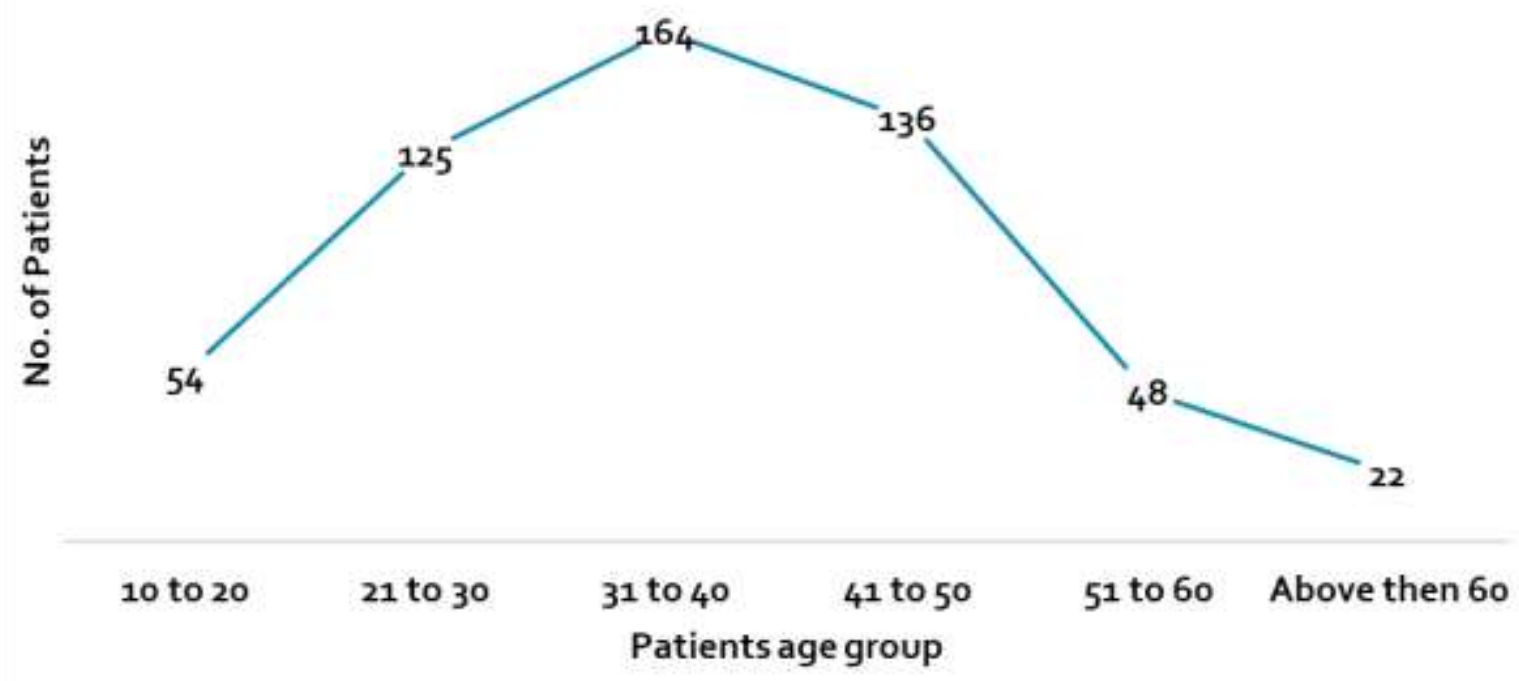

Figure 2-Age-wise distribution of the patients. $(n=549)$

Among 549 patients the most common diagnosis was depression 221(39.46\%), followed by generalized anxiety disorder 49(8.7\%), Headache 45(8.03\%), Body aches or generalized pain 30(5.35\%), Panic Disorder 21(3.75\%), Schizoaffective disorder 17(3.03\%), etc.

A total of 1543 drugs prescribed in which the 702(45.49\%) were antipsychotic and antidepressants. The total no. of drug indication was 560, and 221(31.48\%) of drugs prescribed without any indication. More than one psychotropic drug was used in $96 \%$ of patients. Amitriptyline 137(19.51\%) was the most prescribed drug followed by the Escitalopram 120(17.09\%), Clonazepam 85(12.10\%), Fluoxetine 79(11.25\%), Sertraline 46(6.55\%), Paroxetine 32(4.55\%), Olanzapine 27(3.71\%), Risperidone 25(3.58\%), Trihexyphenidyl 19(2.67\%), etc. [Figure $3.1 \&$ Figure 3.2)]

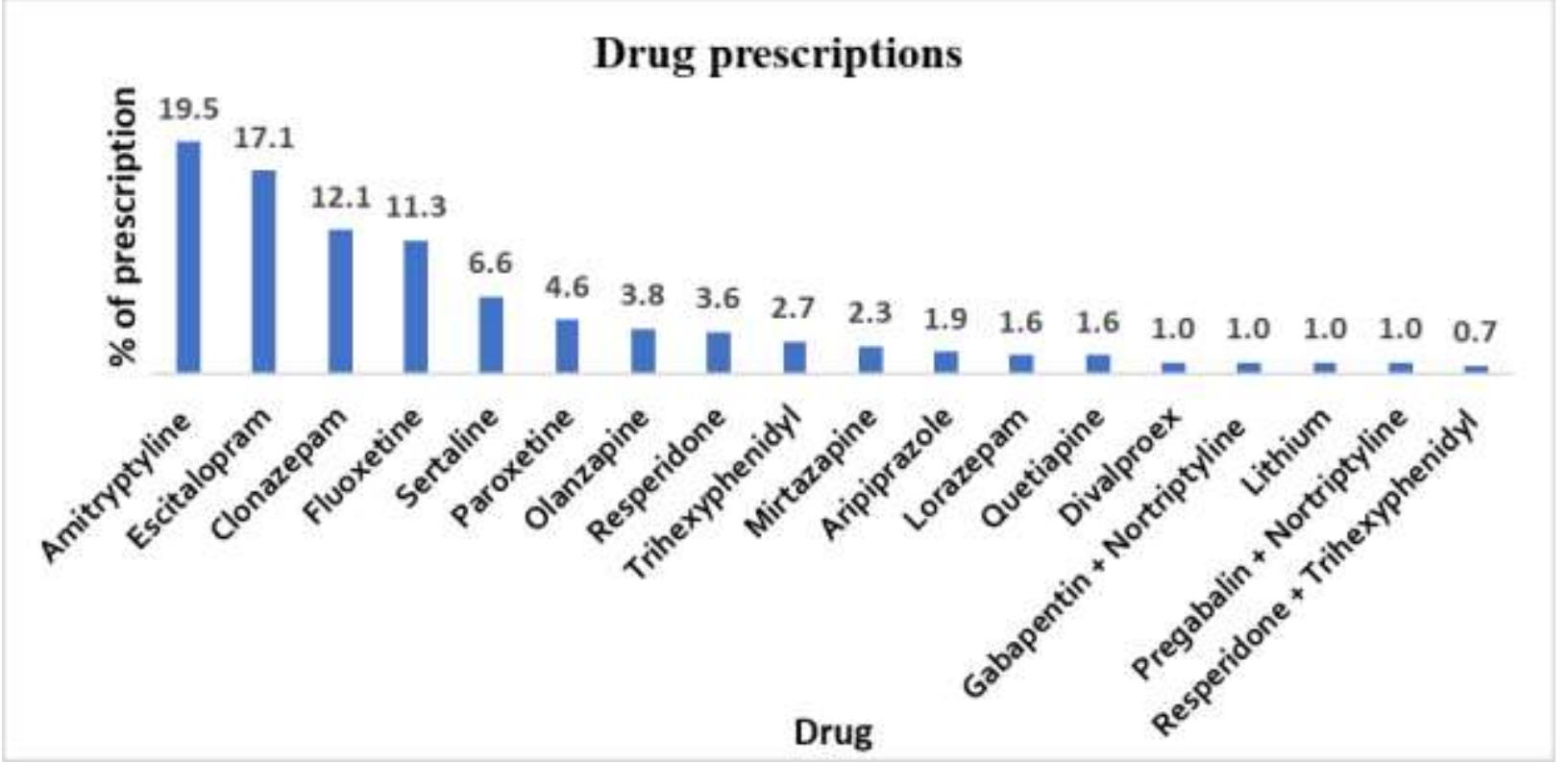

Figure 3.1- Most frequently prescribed drugs $(n=549)$ 


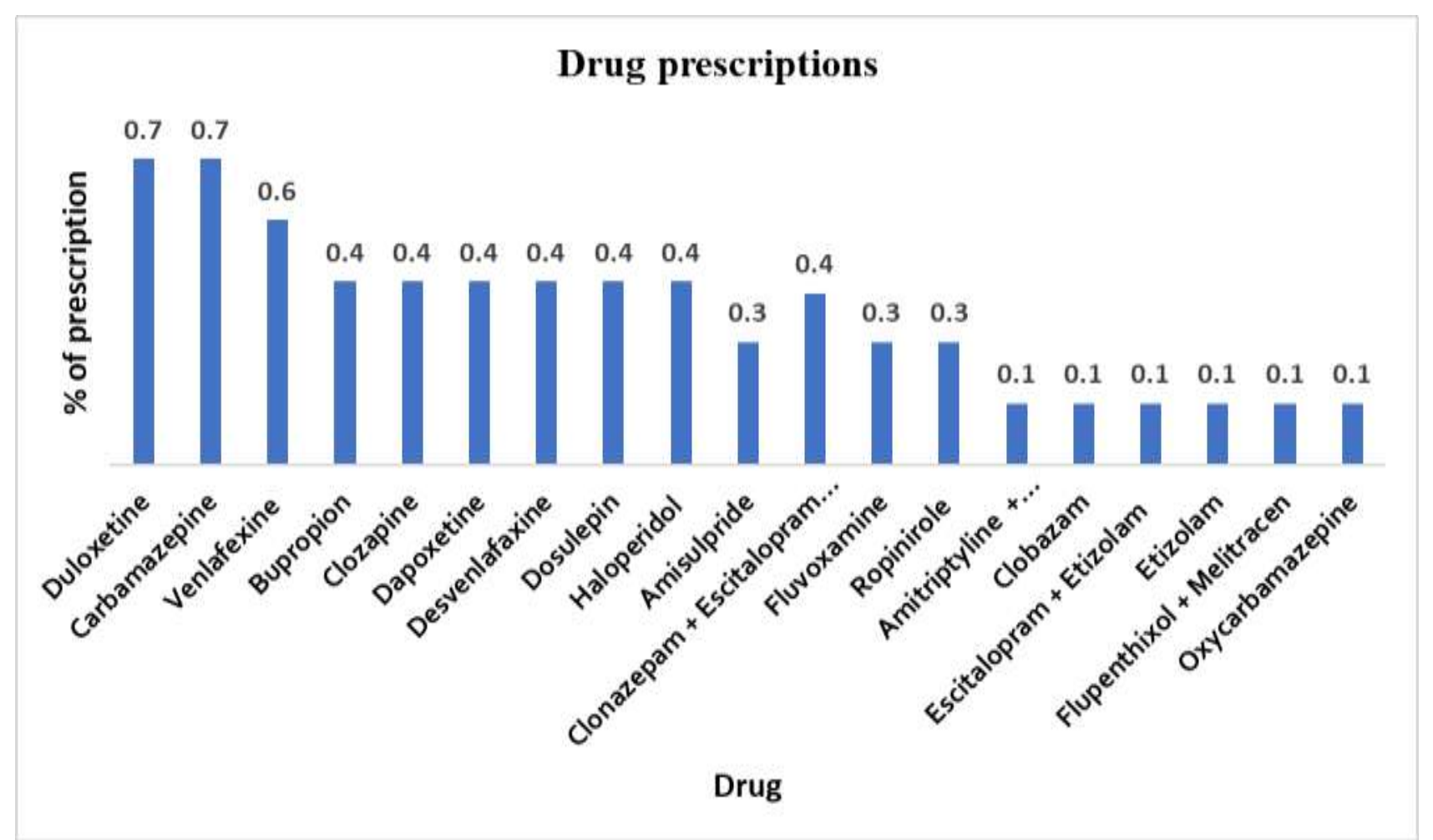

Figure 3.2- Most frequently prescribed drugs $(n=549)$

The most common indication including offlabel prescriptions for antidepressants was depressive disorder followed by generalized anxiety disorder (GAD), migraine, generalized pain, headache, panic disorder, etc. Whereas the common indications for the antipsychotics were Bipolar affective disorder (BPAD), Psychosis, Mood disorder, Bipolar disorder, Unspecified psychosis, Irritable bowel syndrome, Paranoid schizophrenia, etc.
- Distribution of Drug prescriptions from different Outpatient Departments

It is conversant that psychotropic drugs most frequently prescribed in the Psychiatric department where we estimated 403 (73.40\%) patients with a psychotropic prescription, followed by General Medicine 80 (14.57\%), Neurology 25 (4.55\%), Physical Medicine \& Rehabilitation 9 (1.63\%), etc. [Figure-4] 


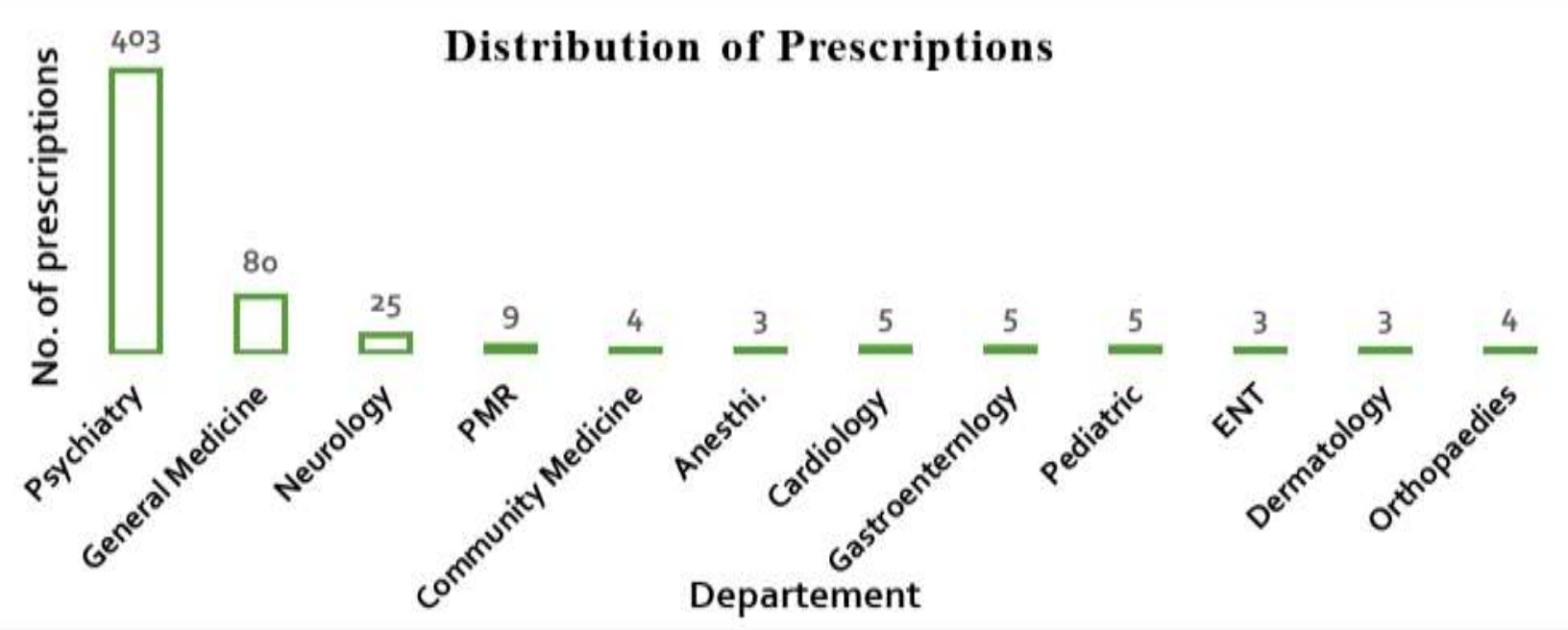

Figure 4- Drug Prescribing distribution in different departments.

- The extent of Off-label drug use

Of the total no. of 702 screened drugs, in which 221(31.48\%) drugs prescribed without stating any indication [Figure-5]. Then and there the 481 drugs were accepted for our targeted study, 203 (42.20\%) drugs were recommended in an off-label manner, 278(57.79\%) drugs were labeled indication [Figure-6].

\section{Prescription Standards Based on Drug Indication}

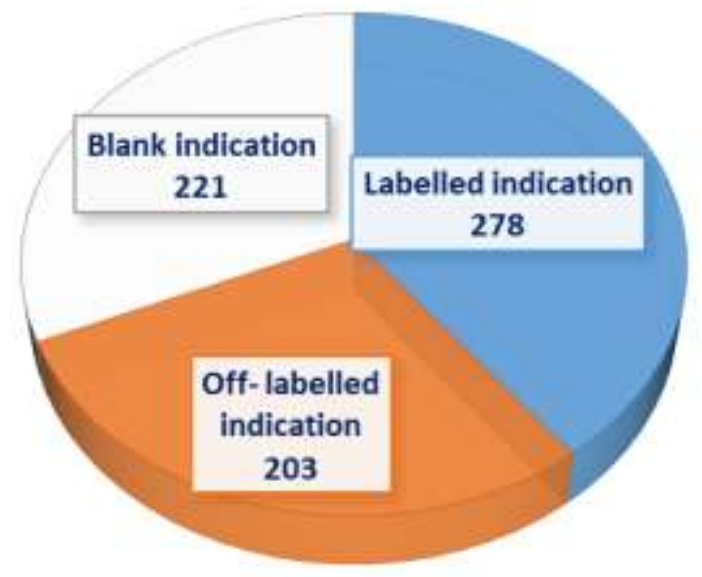

Figure 5 Prescriptions distribution based on indications. 


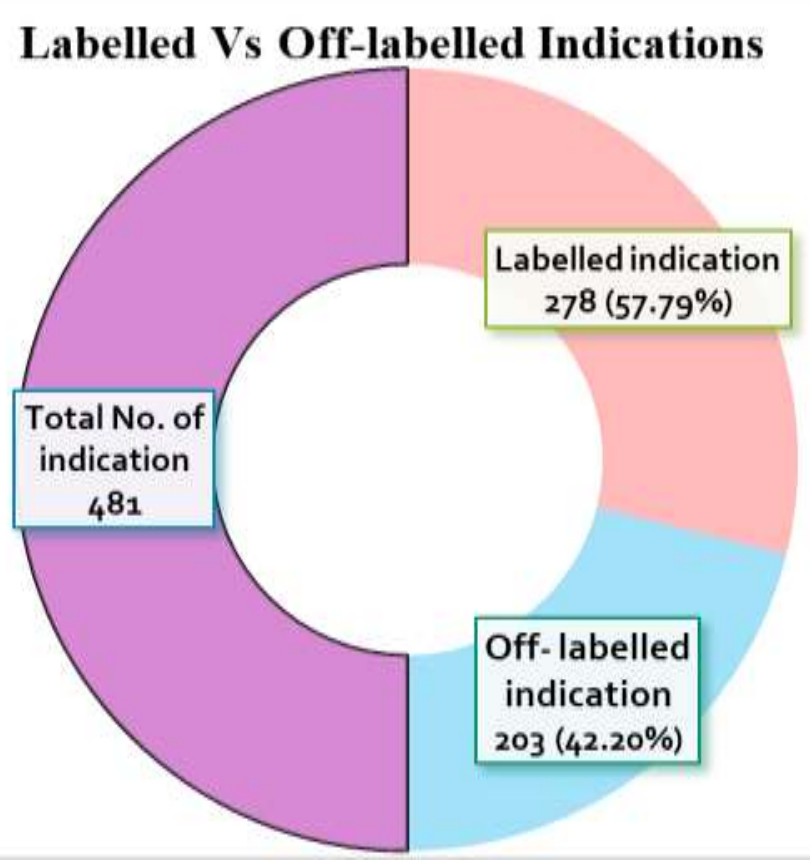

Figure 6 Distribution of drug based on indications.

In the retrospective study, only 19 indications were reported as off-labeled usages. In which most commonly reported ADRs with off-label prescribing was Constipation, weight gain, decrease appetite, decreased libido, dry mouth and decrease sleep. The most common drug with off-label uses was Escitalopram, Amitriptyline, Olanzapine, Fluoxetine, etc.

\section{Interactions of off-label use with age}

There is no significant relation seemed with the particular age group and middle-aged patients were reported for the drug indication based off-labels [Figure-7].

\section{Age Wise Distribution of the Off-label}

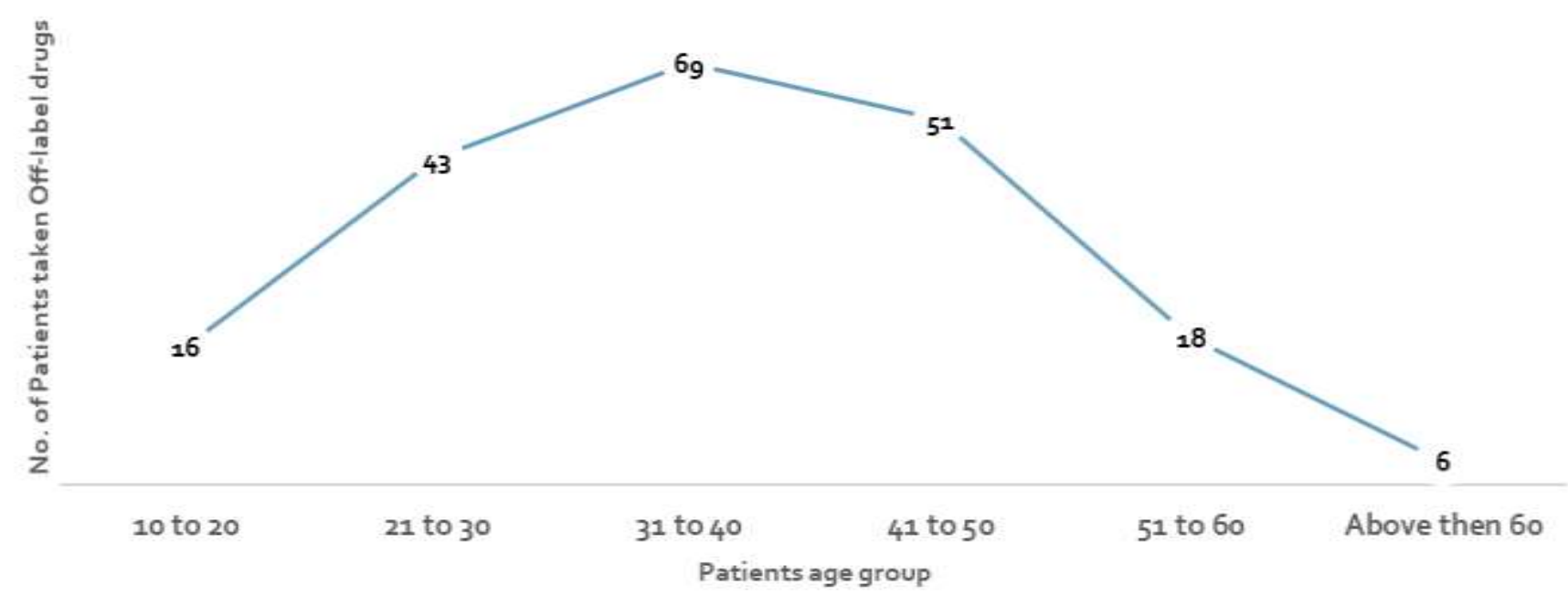

Figure 7- Age-wise distribution of the patients. $(n=549)$

The psychiatric drug that most recurrently prescribed in an off-label manner was Amitriptyline 91(18.91\%), Escitalopram 30(6.23\%), Olanzapine 18(3.74\%), Aripiprazole 12(2.49\%) and Paroxetine 9(1.87\%) [Table 1], [Table 2]. We also noticed that the drugs Benzodiazepines like-Clonazepam, Lorazepam, etc. was the 
commonly prescribed in an off-label manner but it was not part of our study, that is why we have not significantly emphasized on it. Off-label use of atypical or second-generation antipsychotics was seen in $36(7.48 \%)$ of the patients [Table 2]. The patient was not informed at what time the prescriptions were offlabeled and as prescription did not mention off-label use ever [Figure-8].

\section{Commonly prescribed labelled and Off-labelled drugs}

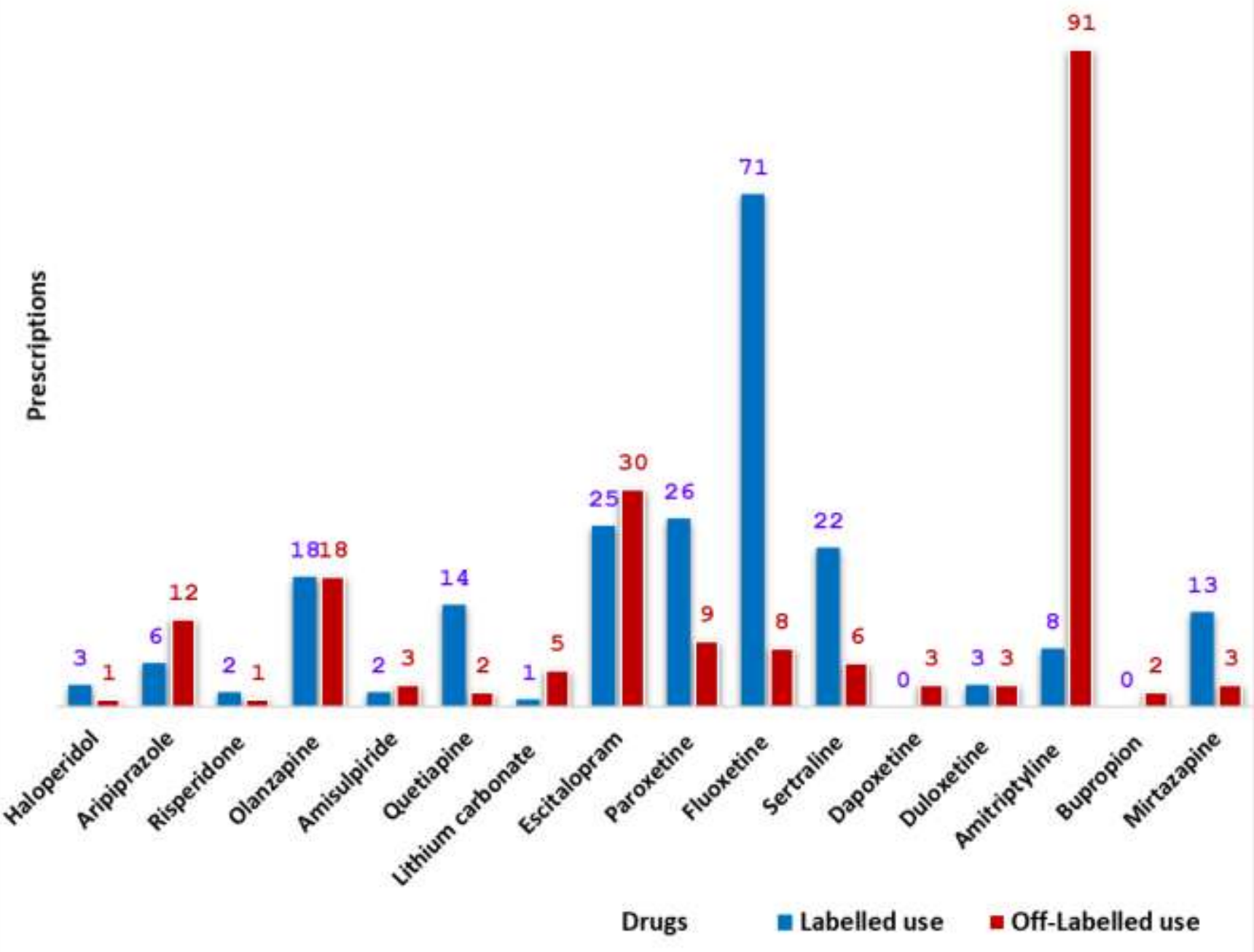

Figure 8- Most commonly prescribed labeled and Off-label drug

Table 1 Off-label indications and most common indications for Antipsychotics

\section{Off-label indications and most common indications for Antipsychotics}

\begin{tabular}{|c|c|c|c|c|c|}
\hline \multirow{2}{*}{$\begin{array}{l}\text { Drug name } \\
\text { by class }\end{array}$} & \multirow{2}{*}{$\begin{array}{l}\text { Total no. of } \\
\text { prescription's }\end{array}$} & \multirow{2}{*}{$\begin{array}{l}\text { Off-label } \\
\text { indication }\end{array}$} & \multicolumn{3}{|c|}{ Treatment indications and \% of prescriptions } \\
\hline & & & Most common & Second most common & Third most common \\
\hline
\end{tabular}




\begin{tabular}{|c|c|c|c|c|c|c|c|c|c|}
\hline & & No. & $\%$ & Indication & $\%$ & Indication & $\%$ & Indication & $\%$ \\
\hline \multicolumn{10}{|c|}{ Classical antipsychotic- Butyrophenones } \\
\hline Haloperidol & 4 & 1 & 0.20 & $\begin{array}{l}\text { Bipolar } \\
\text { affective } \\
\text { disorder }\end{array}$ & 0.41 & $\begin{array}{ll}\text { Acute } & \text { and } \\
\text { transient } & \\
\text { psychotic } & \\
\text { disorder } & \end{array}$ & 0.20 & $\begin{array}{l}\text { Major } \\
\text { depressive disorder }\end{array}$ & 0.20 \\
\hline \multicolumn{10}{|c|}{ Atypical antipsychotics } \\
\hline Aripiprazole & 18 & 12 & 2.49 & $\begin{array}{l}\text { Unspecified } \\
\text { psychosis }\end{array}$ & 0.83 & Somatization dis. & 0.62 & Schizophrenia & 0.62 \\
\hline Risperidone & 3 & 1 & 0.20 & Schizophrenia & 0.41 & $\begin{array}{l}\text { Adult-onset tics } \\
\text { with chronic } \\
\text { dystonia }\end{array}$ & 0.20 & & \\
\hline Olanzapine & 36 & 18 & 3.74 & Psychosis & 0.83 & $\begin{array}{l}\text { Unspecified } \\
\text { nonorganic } \\
\text { psychosis }\end{array}$ & 0.83 & \begin{tabular}{l}
\multicolumn{2}{l}{ Schizoaffective } \\
disorder, Bipolar \\
disorder
\end{tabular} & 0.83 \\
\hline Amisulpiride & 5 & 3 & 0.62 & $\begin{array}{l}\text { Non-Specific } \\
\text { Psychosis }\end{array}$ & 0.62 & $\begin{array}{l}\text { Paranoid } \\
\text { schizophrenia }\end{array}$ & 0.41 & & \\
\hline Quetiapine & 16 & 2 & 0.41 & $\begin{array}{l}\text { Bipolar } \\
\text { affective } \\
\text { disorder }\end{array}$ & 0.83 & $\begin{array}{l}\text { Recurrent } \\
\text { depressive } \\
\text { disorder }\end{array}$ & 0.83 & Depression & 0.62 \\
\hline \multicolumn{10}{|l|}{ Other } \\
\hline $\begin{array}{l}\text { Lithium } \\
\text { carbonate }\end{array}$ & 6 & 5 & 1.03 & $\begin{array}{l}\text { Bipolar } \\
\text { affective } \\
\text { disorder }\end{array}$ & 0.62 & $\begin{array}{ll}\text { Acute } & \text { and } \\
\text { transient } & \\
\text { psychotic } & \\
\text { disorder } & \end{array}$ & 0.41 & $\begin{array}{l}\text { Major } \\
\text { depressive disorder }\end{array}$ & 0.41 \\
\hline
\end{tabular}

Table 2 Off-label indications and most common indications for Antidepressant treatment

\section{Off-label indications and most common indications for Antidepressant treatment}

\begin{tabular}{|c|c|c|c|c|c|c|c|c|c|}
\hline \multirow{3}{*}{$\begin{array}{l}\text { Drug name by } \\
\text { class }\end{array}$} & \multirow{3}{*}{$\begin{array}{l}\text { Total no. of } \\
\text { prescription's }\end{array}$} & \multirow{2}{*}{\multicolumn{2}{|c|}{$\begin{array}{l}\text { Off-label } \\
\text { indication }\end{array}$}} & \multicolumn{6}{|c|}{ Treatment indications and \% of prescriptions } \\
\hline & & & & \multicolumn{2}{|c|}{ Most common } & \multicolumn{2}{|c|}{ Second most common } & \multicolumn{2}{|c|}{ Third most common } \\
\hline & & No. & $\%$ & Indication & $\%$ & Indication & $\%$ & Indication & $\%$ \\
\hline
\end{tabular}




\begin{tabular}{|c|c|c|c|c|c|c|c|c|c|}
\hline Escitalopram & 55 & 30 & 6.23 & Depression & 2.49 & Anxiety & 1.03 & Headache & 1.03 \\
\hline Paroxetine & 35 & 9 & 1.87 & Depression & 3.11 & Panic Disorder & 0.83 & $\begin{array}{l}\text { Somatization } \\
\text { disorder }\end{array}$ & 0.62 \\
\hline Fluoxetine & 79 & 8 & 1.66 & Depression & 11.43 & $\begin{array}{l}\text { Obsessive } \\
\text { compulsive } \\
\text { disorder }\end{array}$ & 0.83 & Neck pain & 0.62 \\
\hline Sertraline & 28 & 6 & 1.24 & Depression & 2.49 & $\begin{array}{l}\text { Anxiety, } \\
\text { dissociative } \\
\text { disorder }\end{array}$ & 1.03 & Mood disorder & 0.62 \\
\hline Dapoxetine & 3 & 3 & 0.62 & $\begin{array}{l}\text { Premature } \\
\text { ejaculation }\end{array}$ & 0.62 & & & & \\
\hline \multicolumn{10}{|c|}{ Serotonin-norepinephrine reuptake inhibitors (SNRIs) } \\
\hline Duloxetine & 6 & 3 & 0.62 & Body ache & 0.62 & Depression & 0.41 & Fibromyalgia & 0.20 \\
\hline \multicolumn{10}{|c|}{ Tricyclic antidepressants (TCAs) } \\
\hline Amitriptyline & 99 & 91 & 18.91 & Headache & 4.15 & Body pain & 3.74 & Abdominal pain & 1.66 \\
\hline \multicolumn{10}{|c|}{ Atypical agents } \\
\hline Bupropion & 2 & 2 & 0.41 & $\begin{array}{l}\text { Restless } \\
\text { syndrome }\end{array}$ & 0.41 & & & & \\
\hline Mirtazapine & 16 & 3 & 0.63 & $\begin{array}{l}\text { Major } \\
\text { depressive } \\
\text { disorder }\end{array}$ & 1.03 & Depression & 0.83 & $\begin{array}{l}\text { Bipolar affective } \\
\text { disorder }\end{array}$ & 0.63 \\
\hline
\end{tabular}

The total no.

of 238 ADR's was reported in the sum of both retrospective and prospective studies. There were 99 men and 140 women patients reported with ADR's [Figure-9].

\section{Gender wise distribution ADR's}

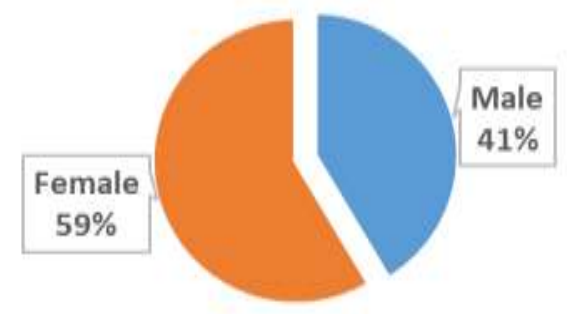

Gender wise distribution of patients with ADR's,

Figure 9

The mean age of patients with ADRs was 36.16 \pm 11.90 years [Figure-10]. 


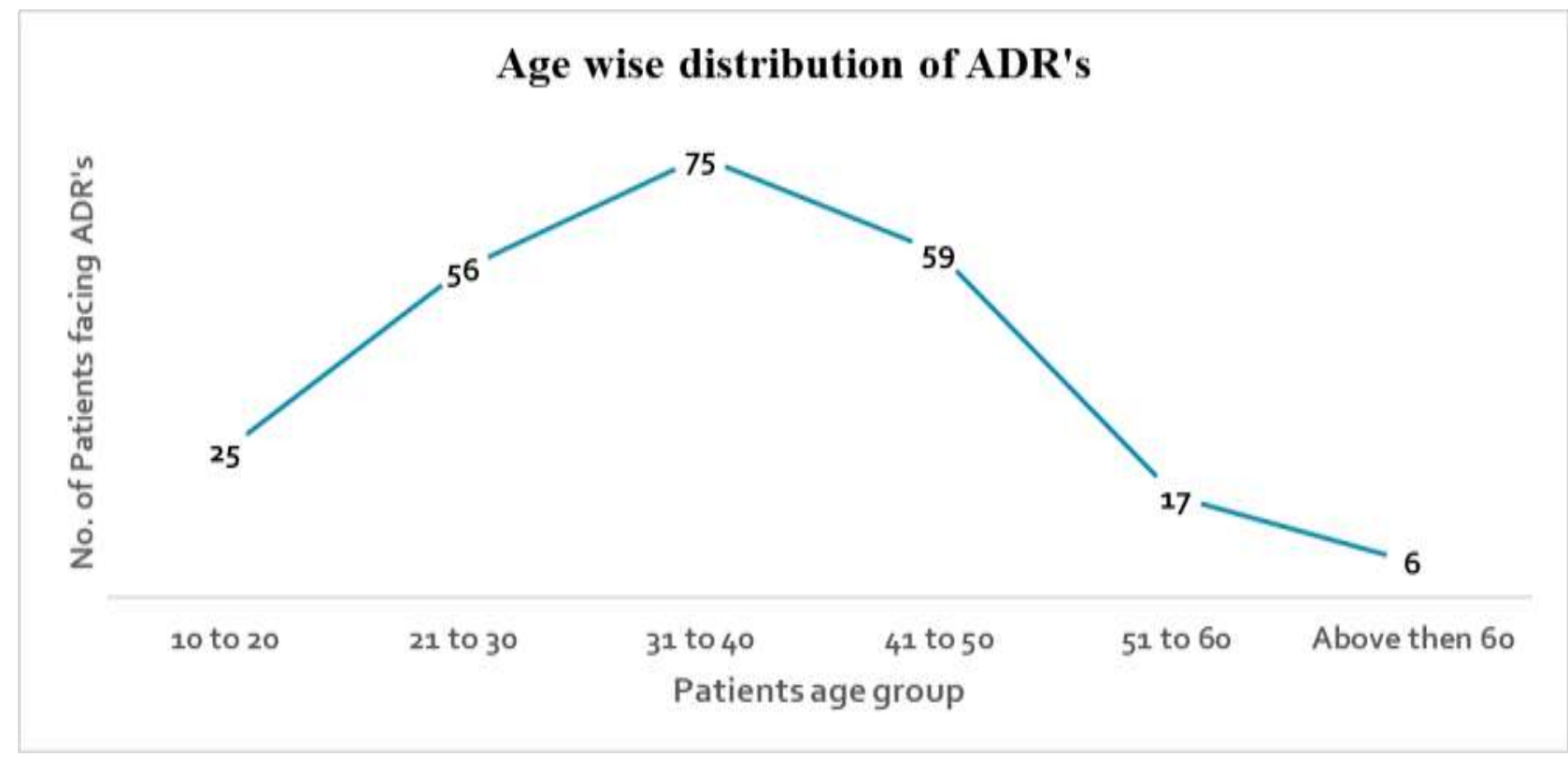

Figure 10 Patients age-wise distribution of ADR's

The most common group of the drug causing ADRs was SSRI's 192(34.9\%) followed by tricyclic antidepressants 14(2.55\%), atypical antipsychotics 12(2.18\%) and SNRI's 5(0.09\%) [Figure-11]. The most frequently drug causing ADR was reported as Escitalopram 83(34.72\%) followed by Fluoxetine 59(24.68\%), Sertraline 33(13.80\%), Paroxetine 15(6.27\%) and Amitriptyline 14(5.85\%).

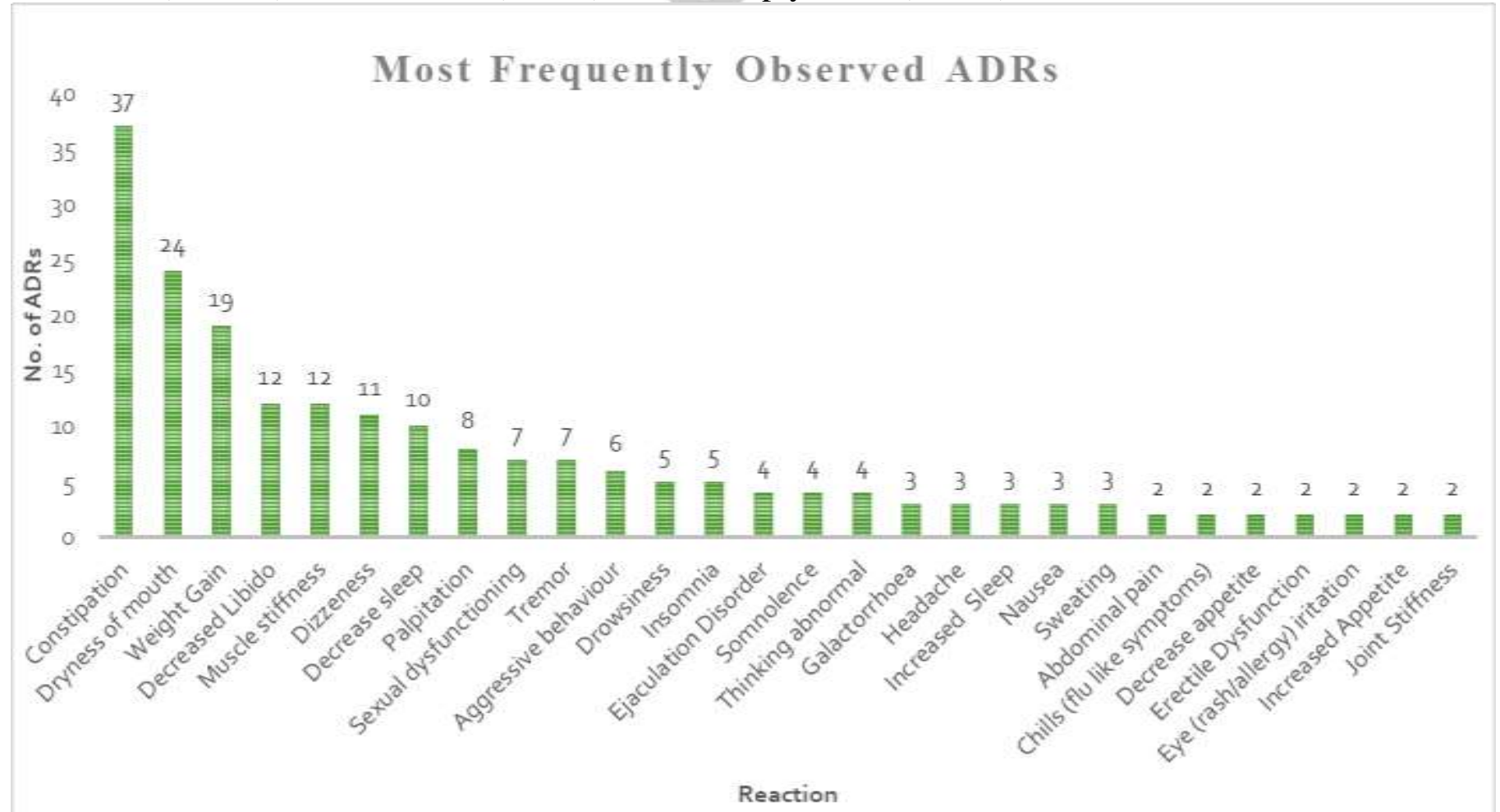

Figure 11 The most frequently observed Adverse drug reactions (ADRs) in the study.

- ADRs associated with antipsychotic and antidepressant drugs prescribed for labeled indications: 
- Among SSRI's, Escitalopram, Fluoxetine, Sertraline, and Paroxetine were the most common causal drugs causing Constipation, decrease appetite, Decreased libido, Dizziness, Dry Mouth, Insomnia, Muscle stiffness, Palpitation, Sexual Dysfunction, Aggressive behavior, Restlessness, Tremor and Weight Gain.

- Atypical antipsychotics drugs including Quetiapine, Risperidone, Olanzapine, Aripiprazole, and Amisulpiride were commonly prescribed and their ADR's observed in the study were Erectile Dysfunction, Tardive Dyskinesia, Rise in salivation, Amenorrhea, Drowsiness, Pancytopenia, Suicidal thoughts, and Weight gain.

- SNRI's drugs Venlafaxine and Duloxetine were infrequently prescribed and few ADR's were reported like Sexual Dysfunction, Weight Gain, Palpitation, Dry Mouth, and Constipation.

- In the retrospective analysis, Orofacial dyskinesia with prolonged use of Sertraline was reported as a serious adverse reaction in one of the patients of depressive disorder.

- ADRs associated with antipsychotic and antidepressant drugs prescribed for offlabeled indications:

- The most prescribed tricyclic antidepressant drug in off label manner was Amitriptyline
- for treatment of Headache, Fibromyalgia, Somatization disorder, etc. associated with commonly observed ADR's such as dry mouth, constipation, drowsiness, dizziness, and galactorrhoea.

- SSRIs like Escitalopram and tricyclic antidepressant-like Imipramine were prescribed off- labeled for treatment of Dhat Syndrome or Hyperarousal disorder i.e. (spontaneous and involuntary discharge of semen)

- SNRIs such as Venlafaxine and Duloxetine reported delayed ejaculation as the most prominent adverse effect when prescribed for treatment of depression and other depressive disorders. Therefore, the drug was found to be a potential candidate for the treatment of premature ejaculation hence, it was being judiciously prescribed to several patients of premature ejaculation as an off-labeled indication.

- According to the WHO-UMC scale, the majority of the ADRs were categorized as possible (70.10\%), probable/likely $(21.80 \%)$ and certain $(8.10 \%)$ in nature [Figure-12]. 


\section{Causality assessment of ADRs according to WHO-UMC scale}

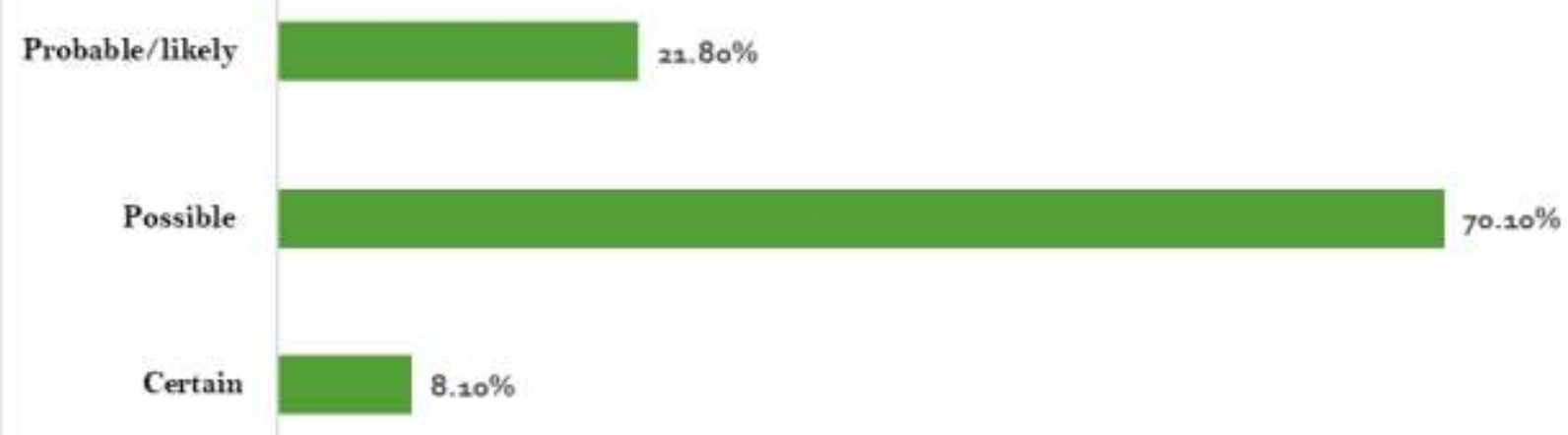

Figure 12-Causality assessment of observed ADRs according to WHO-UMC scale.

\section{DISCUSSION}

This study as aimed at analyzing the magnitude of off-label prescribing and finding out the extent, pattern, in addition to ADRs associated with Off-label prescribing, provides scientific support for off-label antidepressants and antipsychotics prescriptions.

This study has been done with the aim to discover the magnitude of off-label prescribing of antidepressants and antipsychotic drugs and associated adverse drug reactions. The sample size of this study was (549) which is found to be higher than the previous Indian studies on off-label prescribing of antidepressants and antipsychotic drugs amounting to $42.20 \%$. Amitriptyline was the most prescribed drug in an off-label manner, followed by Escitalopram, Olanzapine, and Aripiprazole in the antidepressant and antipsychotic drug category. Moreover, we also noticed that benzodiazepines belonging to the class of sedative and hypnotics such as Clonazepam, Lorazepam, and Clobazam were also being prescribed in an off-label manner for the treatment of bipolar disorder and restless leg syndrome, but it was not part of our study, that's why we have not significantly emphasized on it.

During the retrospective analysis of ADR records, very few cases of off-label prescribing trends were noted because the recorded data were mainly obtained from spontaneous reporting rather than targeted reporting, which was the main goal of our present study. And no extreme outcomes such as death in any case was not witnessed by these drugs.

In this study, the mean age of the patients was noted to be 37.34, and the male: female ratio was 1:1.3, indicating a higher incidence of the female population as compared to previous Indian studies which reported a higher population of males. Here was no significant relation seemed with the particular age group and middleaged patients were reported for the drug indication based off-labels.

In our study mean the number of drugs prescribed per patient was 2.81 which is lower than the previous Indian studies showing a mean value of $3.6 \pm 1.42 \mathrm{SD}$, this could be attributed to associated co- 
morbid conditions and difference in prescribing practices. (36) on the other hand, this outcome was equivalent to another Indian study which reported a mean of $2.01 \pm 1.03$, which focused on Psychotropic drug utilization. (16)

The off-label prescribing in our study is $42.20 \%$ which is approximately similar to the previous study done by Darshan Kharadi, et al., in a Tertiary Care Teaching Hospital, Ahmedabad, (Gujarat), reporting a prevalence of $39.5 \%$ of off-label prescription of psychotropic medications exclusively. Moreover, while comparing the results of above two studies with the of offlabel medication prescribing in French general practice reported by Drogo u F, et al. (2017) only $18.5 \%$ of off label prescribing trends were observed indicating a non-targeted off label drug utilization approach. (17)

Discussing the results of another study by Rebecca Rajan, et al., done on 300 patients in a tertiary care hospital in India on the off-label prescribing pattern in addition to associated adverse drug reactions in pediatric inpatients $35.79 \%$ drugs were prescribed in an off-label manner according to BNFC and $27.9 \%$ as per Micromedex. (18), (19).

In our study, delayed ejaculation an adverse effect associated with the use of antidepressants such as Escitalopram, Imipramine, Paroxetine, and Duloxetine was found to be a classical example of an effect which may be therapeutic in one context but side effect in another context, because the unwanted side effect of these drugs proved to be beneficial and potential treatment of patients suffering from premature ejaculation.
The occurrence of ADR's was high in middle age group of patients (31.5 \%) in our setting. The other most frequently observed adverse effects with the use of antidepressants were constipation followed by dryness of the mouth, decreased libido, weight gain, etc. while adverse effects of antipsychotics included somnolence, sexual dysfunction, weight gain, drowsiness, and galactorrhea in women.

In our setting wide variability was noticed in prescribing practices among clinicians by means of the physician specialty, we observed that the general practitioner, neurologist, pediatricians, and cardiologist were also involved in off-label prescribing as compared to the physician specialized in psychiatry.

Many off-label prescriptions were based on the clinical presentation of the symptoms irrespective of good scientific confirmation of the recommended drug as a standard treatment therapy. Therapeutic efficacy assumptions were supported by sufficient evidence of anyone drug of the same class being prescribed in an off-label manner.

The outcomes of the present study describing the extent and patterns of prescriptions will provide scientific support for off-label practices of antidepressants and antipsychotics recommendations.

\section{LIMITATIONS}

- The setting up of our off-label drug study within Indian tertiary care teaching hospital included the database of drug package insert (US-FDA) which used to distinguish the drug indications. Although the National Formulary of India (NFI)2016, be available 2020 November Edition | www.jbino.com | Innovative Association 
as a manual with a clinically oriented summary of medicinal information about the selected medicines, it was not used in our study as a reference database because it comprises limited drugs.

- The study was a single-center study with the scale of a little sample because of the constricted duration of the study.

- Off-label prescribing and ADR's was identified on the premise of physicians' notes within which subjective bias is also enclosed such as decision making, or evaluation based on personal, poorly measurable, and unverifiable data.

- We only studied off-label prescribing in terms of indication, route of administration and age, without including the dosage, and drug interaction risks.

\section{CONCLUSION}

The term 'Off-label' has been elucidated in many ways but there is no formal definition for 'off-label recommendation' although an international accepted European definition permits for the assessment and association of better off-label prescriptions. In our study, we noticed that the prescribing of off-label medicines is common in psychiatric practice, but this is not restricted to psychiatric setup only; other departments are also involved in offlabel prescriptions of psychotherapy drugs used in different ailments.

As discussed above, the drugs such as Imipramine, Paroxetine, and Duloxetine was widely prescribed in off-label manner for the premature ejaculation, the various literature and previous studies also demonstrated the good results of these drugs for the same purposes and including the present study also strengthening these uses. So, this time need to be shift this offlabel indication into the labeled indication for the premature ejaculation.

The data generated from this study will contribute to the scientific database of off -label prescribing trends in clinical practice. Besides, the utilization of various drug formularies may also help to improve the off-label prescribing of drugs in general practice, presenting drug benefits and possibilities of adverse drug conditions.

It is imperative that the system considers eprescribing methods for better utilization of approved drugs with off labeled indications by preventing unauthorized and injudicious drug use. Electronic health record registers have the potential to make a crucial part of the effective postmarketing drug surveillance system for the obseryance and estimating off-label medicine uses.

At this point, there is a need to boost awareness for the off-label prescription issues among clinicians and other healthcare professionals. Off-label prescribing is not always considered irrational or illogical, especially when the clinical practice acts in accordance with the recommended guidelines mentioned in the summary of product characteristics (SPC).

We conclude that outcomes of our study have highlighted an important need to ensure a lot of scientific evidence about the risks and benefits of off-label medications expanding the accountability of doctors towards safe medication practices.

\section{CONFLICT OF INTEREST}

The authors have no conflicts of interest to declare. 


\section{ACKNOWLEDGMENTS}

The authors would like to thank the Faculty, Senior Residents and PhD scholars of the Department of Pharmacology, AllMS Rishikesh, Department of Pharmacology, AllMS, Rishikesh, for her help in identification and screening of the drug indications and diagnosis.

With sincere note of gratitude, Author specially thanks to Prof. (Dr.) Shailendra Handu, Head of the department, Department of Pharmacology, AllMS, Rishikesh, and Mr. Pawan Bagiyal Deputy Manager of HLL Life-care Limited, for his most valued suggestions and encouragement during the course of study.

\section{DATA AVAILABILITY STATEMENT}

The data that support the findings of this study are available from the corresponding author upon reasonable request.

PI statement: The authors confirm that the Principal Investigator for this paper is Dr. Puneet Dhamija and that he had direct clinical responsibility for the subjects

\section{REFERENCES}

1. Dresser, R., \& Frader, J. (2009). Off-label prescribing: a call for heightened professional and government oversight. The Journal of Law, Medicine \& Ethics, 37(3), 476-486.Gota V, Divatia J. Off-label use of drugs: An evil or a necessity? Indian J Anaesth. 2015;59(12):767.

2. Haw, C., \& Stubbs, J. (2007). Off-label use of antipsychotics: are we mad?. Expert opinion on drug safety, 6(5), 533-545.
3. Wong, J., Motulsky, A., Abrahamowicz, M., Eguale, T., Buckeridge, D. L., \& Tamblyn, R. (2017). Off-label indications for antidepressants in primary care: descriptive study of prescriptions from an indication based electronic prescribing system. bmj, 356, j603.

4. Kant, A., Bilmen, J., \& Hopkins, P. M. (2019). Adverse drug reactions. In Pharmacology and Physiology for Anesthesia (pp. 130143). Elsevier.

5. Medicines E, Lists EM. Essential medicines and health products Essential medicines. 2015; (March):3-5. Available from: http://www.who.int/medicines/areas/tradit ional/congress/beijing_declaration/en/

6. Convertino, I., Ferraro, S., Blandizzi, C., \& Tuccori, M. (2018). The usefulness of listening social media for pharmacovigilance purposes: a systematic review. Expert opinion on drug safety, $17(11), 1081-1093$.

7. World Health Organization. (2004). Pharmacovigilance: ensuring the safe use of medicines (No. WHO/EDM/2004.8). World Health Organization.

8. Kalaiselvan, V., Srivastava, S., Singh, A., \& Gupta, S. K. (2019). Pharmacovigilance in India: present scenario and future challenges. Drug safety, 42(3), 339-346.

9. Lihite, R. J., \& Lahkar, M. (2015). An update on the pharmacovigilance programme of India. Frontiers in pharmacology, 6, 194.

10. Nordqvist C. All about antidepressants. Med News Today [Internet]. 2018; (February 2018):1-13. Available from: https://www.medicalnewstoday.com/kc/a ntidepressants-work-248320

11. CMS. Antidepressant Medications: Use in Adults FDA-Approved Indications for Antidepressant Medications in Adults. 
2015;(October). Available from: https://www.guideline.gov

12. Maust, D. T., Kim, H. M., Chiang, C., \& Kales, H. C. (2018). Association of the Centers for Medicare \& Medicaid Services' national partnership to improve dementia care with the use of antipsychotics and other psychotropics in long-term care in the United States from 2009 to 2014. JAMA internal medicine, 178(5), 640-647.

13. Chang, S. C., \& Shen, W. W. (2019). Antidepressant therapy in patients with cancer: A clinical review. Taiwanese Journal of Psychiatry, 33(1), 13.

14. Crystal, S., Olfson, M., Huang, C., Pincus, H., \& Gerhard, T. (2009). Broadened Use Of Atypical Antipsychotics: Safety, Effectiveness, And Policy Challenges: Expanded use of these medications, frequently off-label, has often outstripped the evidence base for the diverse range of patients who are treated with them. Health affairs, 28(Suppl1), w770-w781.

15. Thakkar, K. B., Jain, M. M., Billa, G., Joshi, A., \& Khobragade, A. A. (2013). A drug utilization study of psychotropic drugs prescribed in the psychiatry outpatient department of a tertiary care hospital. Journal of clinical and diagnostic research: JCDR, 7(12), 2759.

16. Drogou, F., Netboute, A., Giai, J., Dode, X., Darmon, D., Kassai, B., \& Letrilliart, L. (2019). Off-label drug prescriptions in French general practice: a cross-sectional study. BMJ open, 9(4), e026076.

17. Rajan, R., Peter, S. M., Kurian, V. M., Ansari, R., Pawar, S., \& Kalrao, V. (2019). The practice of off label prescribing and associated adverse drug reactions in pediatric inpatients in a tertiary care hospital in India. Journal of Pharmaceutical Health Services Research, 10(1), 29-34.

18. Kharadi, D., Patel, K., Rana, D., \& Patel, V. (2015). Off-label drug use in Psychiatry Outpatient Department: A prospective study at a Tertiary Care Teaching Hospital. Journal of Basic and Clinical Pharmacy, 6(2), 45.

19. Vijay, A., Becker, J. E., \& Ross, J. S. (2018). Patterns and predictors of off-label prescription of psychiatric drugs. PLoS One, 13(7), e0198363.

20. Rhee, T. G., Mohamed, S., \& Rosenheck, R. A. (2018). Antipsychotic prescriptions among adults with major depressive disorder in office-based outpatient settings: national trends from 2006 to 2015. The Journal of clinical psychiatry, 79(2). 